\title{
THE VISCOSITY COEFFICIENT OF AIR, WITH AN : INQUIRY INTO THE EFFECT OF THE RÖNTGEN RAYS THEREON.
}

By Frederick G. Reynolds.

\section{HistoricAL.}

$T^{1}$ E phenomena of viscosity have claimed the attention of investigators for many years ; but while the general truths may be said to be settled, there have always existed many differences of detail in which one may find a justification for further effort in the same field.

By the viscosity of a gas is meant the resistance which it offers to a continuous change of form divided by the rate at which that change is effected. The coefficient of viscosity may perhaps be best understood by considering a stratum of the gas infinite in extent. If this stratum were enclosed by two parallel planes at a distance $d$ centimeters from each other and if one of these planes were to move parallel to the other with a velocity of $v$ centimeters per second, keeping always in the same direction, till the gas embraced takes up its final velocity thus imparted, this velocity would decrease uniformly as we pass from the moving plane towards the other. If again the strata in contact with the two planes have the same velocity as the planes themselves, the strata will decrease in velocity $v / d$ centimeters per second for every centimeter we depart from the moving plane. The friction between any two contiguous strata will then be the same as between either plane and the stratum in contact with it. If this friction be denoted by a tangential force $F$ on every square centimeter of surface then $F=U v / d$ where $U$ is the coefficient of viscosity of the gas. The measurement of the internal friction or viscosity of a gas is the determination of the value of this coefficient.

The property which enables one layer to drag along another might in liquids be looked upon as a cohesion acting in opposition 
to the motion, but in the case of a gas we must look for another explanation. In the light of the kinetic theory we look upon the gas as manifesting itself by the very rapid motion of its molecules. When two layers are moving therefore with unequal velocities, the molecules from the faster moving layer penetrate the slower moving one with their faster forward velocity and vice versa, so a measure of the friction would be the momentum which is thus carried over. The heat motion of the moleccules is so great (being at $0^{\circ} \mathrm{C}$., a mean velocity of 447 meters per second), that it is not affected by the comparatively slow forward motion of the molecules. It would naturally follow that this friction would increase with an increase of the temperature, for the speed of the molecules increases with the temperature being proportional to the square root of the absolute temperature. That the friction is independent of the density seems paradoxical at first, but the theory is at least justified when we consider that the transfer is made by the molecules and is greater as their number and activity are greater hence as the density is greater, but at the same time the transfer takes place in layers whose distance apart may be traversed by the molecules and as the density increases, this distance is restricted so that it is possible that the combined result of the two causes should produce a constant effect.

The methods of approaching and handling the investigations into the viscosity of fluids, both theoretical and practical may be divided into four general classes:

I. By their transpiration through capillary tubes. In this phase of the investigation Poiseuille ${ }^{1}$ and Graham ${ }^{2}$ were the pioneers, the former as to liquids and the latter as to gases.

II. By the swinging of pendulums. This method was followed by Baily. ${ }^{3}$. Bessel ${ }^{4}$ and Du Buat ${ }^{5}$ whose work is discussed in a paper by Stokes " On the internal Friction of Fluids on the Motion of Pendulums."

III. By the torsional vibrations of an immersed disc, first adopted by Coulomb. ${ }^{7}$

1 Mém. de Savants Étrangers, 1846 , IX., p. 433.

2 Phil., Trans., r846, CXXXVI., p. 573 ; r849, CXXXIX., p. 349.

3 Phil. Trans., 1832 .

+ Berlin Acad., 1826

5 Principes d'Hydraulique, 1786.

${ }^{6}$ Cambridge Phil. Trans., I850, IX., pt. 2

7 Mém. de l'Institut National, III., p. 246. 
IV. By the torsional vibrations of a vessel filled with the fluid in question. This might be considered as a development of the preceding method.'

Each method seems to have its practical and theoretical advantages and disadvantages and the discordant results attending the early efforts in each have since been brought more closely into harmony through criticism and refinements of method. In speaking of the transpiration and torsion methods Meyer remarks of the discrepancies "als begründet in den Annahmen, welche zur Gewinnung brauchbarer Formeln in die theoretische Entwickelung eingeführt würden; die dabei eintretenden Vernächlässigungen wären in dem Falle schwingender Scheiben derart, dass der Coefficient zu gross, in dem Falle des Ausflusses durch Capillarröhren derart dass er zu klein erhalten müsste; die wahren Werthe würden also zwischen der Resultaten dieser beiden Methoden liegen." Which method comes nearer to the truth is not decided but the possible objection to the transpiration experiments lies in the difficulty of measurement of the diameters of the tubes and also in the fact that on account of the smallness of the bore one cannot be certain that the action between the molecules of the gas and of the substance of the tube does not affect the result. The pendulum method seems to be considered capable of great accuracy; but in the theory applicable to it Baily made the error of considering that the viscosity is dependent on the density. A revision of his results on the basis of a correct hypothesis has been promised but does not seem to have been made. The difficulties or objections connected with the method of a vibrating disc seem to be less than in the transpiration method and it may be for this reason that it has been the method generally selected by the later investigators; but the trouble here lies in the necessity of accounting properly for the effect of the motion of the medium near the edge of the discs. As a result of Maxwell's ${ }^{2}$ analysis and deductions, given in I 860, both he and Meyer $^{3}$ started to practically demonstrate the truth of the same, using as a basis of their investigations the

${ }^{1}$ Helmholtz and Pietrowski, Sitzungsber. der kk. Akad., April, I860.

2 Phil. Mag., 1860, (4), XIX., p. 31 ; Phil. Trans., I866, CLVI., p. 249.

${ }^{3}$ Pogg. Ann., 1865, CXXV., p. 177 . 
method adopted by Coulomb, but Meyer altered the earlier method in so far as to substitute three oscillating discs with a common axis instead of the one used by Coulomb. These plates were so arranged that it was possible to separate them, thereby exposing six surfaces, or to place them together, exposing only the two. In this way the friction on the exposed parts of the hanging system such as the mirror, etc., as well as the internal friction of the wire itself could be eliminated by considering the difference of the effects obtained when the plates were apart and together. Maxwell improved on this by inserting four fixed plates between the moving ones, which had the effect of causing the friction of the gas to exert a greater resistance and therefore one more easily measured, an advantage which was immediately recognized by Meyer ${ }^{1}$ himself. A further advantage of Maxwell's method lies in the fact that his deductions give the viscosity coefficient directly, whereas Meyer's deductions lead to the square root which would cause the effect of any error to be increased. As a consequence Maxwell's results showed a better agreement in the effort to verify the independence of the coefficient and the pressure within the range of his observations, viz: from one to one sixtieth atmospheres. In 1887 as a result of a correction suggested by Koenig ${ }^{2}$ an improvement was made by Meyer in his method and he calculated his results again on the improved theory. ${ }^{3}$

This independence of the viscosity and the pressure cannot be expected to hold in the limiting cases, as would follow from a consideration of the theory. The density and the free path enter we have seen as factors but when the former approaches o the latter approaches $\infty$ which would cause this phenomenon to fall outside of a development where only finite densities and free paths are considered.

Investigations on this point at low pressure were taken up by Kundt and Warburg, ${ }^{4}$ who followed Maxwell's methods and found that below a pressure of one sixtieth atmosphere there was a

1 Pogg. Ann., i871, CXLIII., p. 14.

2 Wied. Ann., 1887, XXXII., p. 193.

${ }^{3}$ Wied. Ann., XXXII., p. 642 ; Sitzungber. d. Münchener Akad., I887, XVII., p. 343 .

${ }^{4}$ Monatsber. d. Berl. Akad., I875, p. r6o ; Pogg. Ann., I875, CLV., pp. 337, 525. 
marked diminution in the logarithmic decrement from which the viscosity coefficient is calculated. They however found an explanation of this in a phenomenon which they called slipping or (external friction) by which is meant the sliding of the medium along the bounding surface as distinguished from the sliding of one layer of the medium along another layer; and they explained this falling off as not caused by a decrease of the coefficient of viscosity but by an increase of the slipping at the lower pressure. Even a highly polished surface must in comparison with the molecules of the gas be considered rough, and under ordinary pressures a sliding along this, especially since the forward motion is very slow, is practically impossible, but this would not be the case in a very rare medium. By the term coefficient of slip they designated the ratio of the internal to the external friction, with the result that between the pressures of .6 and 20 millimeters of mercury the value of the coefficient of slip was found to be inversely proportional to the density of the gas and very nearly equal to the free path of the molecules. Therefore the external friction is directly proportional to the density. Warburg ${ }^{1}$ experimented further on the external friction by the transpiration method and obtained smaller values for the coefficient of slip but Breitenbach ${ }^{2}$ later obtained results nearer the earlier ones.

The correctness of this explanation of Kundt and Warburg for the sudden falling off the logarithmic decrement was later proven by Crookes ${ }^{3}$ on a theory developed by Stokes, ${ }^{4}$ wherein he used his vacuum tubes with vertically suspended strips of mica thereby excluding the possibility of any external friction. The results of these investigations show the independence of viscosity and pressure down to pressures so low as to be no longer accurately measured. However, at much higher vacuums there is a break in the constancy.

At extremely high pressures the law does not hold, but this might also be expected from the assumptions in the theory. Start-

\footnotetext{
${ }^{1}$ Pogg. Ann., 1876, CLIX., p. 399.

2 Wied. Ann., 1899, LXVII., p. 826.

${ }^{3}$ Phil. Trans , I881, CLXXII., p. 387.

4 Phil. Trans., I88I, CLXXII, p. 435.
} 
ing with the hypothesis that the particles traverse straight paths between their successive encounters with each other, the curved paths traversed during the period of actual encounter would be negligibly small, at ordinary densities or at low densities; but this would not be the case when the density becomes very great. The law considers the molecules unchangeable and the dissociation of the molecules under this extreme condition may contribute to this variation. This would be particularly true in the consideration of vapors. Warburg and Babo ${ }^{1}$ have shown in the case of carbonic acid that the coefficient of viscosity increases with the density at pressures from 30 to I 20 atmospheres, which law seems to hold for other gases as well.

In 1866 Meyer $^{2}$ published a theory where in assuming the independence of pressure upon the friction, he gave a law governing the speed of flow of gases through capillary tubes which corresponded with the law found by Poiseuille for liquids and which, by considering the amount of gas transpired in a given time leads to the value of the coefficient of friction. His calculations from the results of Graham's observations proved the correctness of his assumption. He obtained for the coefficient of viscosity of the air at $0^{\circ} \mathrm{C}$. the values .000I7I, .000I70, .000I74 and he also gave the coefficients. for nineteen other gases. Obermayer ${ }^{3}$, Puluj ${ }^{4}$ and Mutel following this method obtained for air the values .000I67, .000I80, .000 I 72 respectively.

As to the fact of the increase of the viscosity with the increase of the temperature there can be no doubt, but as to the rate of such change there is not such an agreement among the different investigators. Maxwell first put it as increasing directly as the absolute temperature or proportional to $(\mathrm{I}+a \vartheta)$ where $\vartheta$ is the temperature from the freezing point and $a$ is the coefficient of expansion. Later experiments show that for air at least it does not increase so rapidly. Efforts were made to represent the change by a factor of the form $(\mathrm{I}+\imath \vartheta)^{n}$ where $n$ was first given as three fourths but later Barus ${ }^{5}$

${ }^{1}$ Weid. Ann., 1882, XVII., p. 390 ; Sitz. d. Berl. Akad., I882, p. 509.

${ }^{2}$ Pogg. Ann., I866, CXXVII., pp. 253, 353.

${ }^{3}$ Carl's Rep., I876, XII., p. I3.

${ }^{4}$ Wien. Ber., I874, LXIX., (2), p. 287 ; LXX. (2), p. 213.

${ }^{5}$ Bull. of the U. S. Geol. Surv., No. 54, Washington, 1889; Wied. Ann., 1889, XXXVI., p. 358 . 
adopting the transpiration method and with a range of temperature from $0^{\circ}$ to $1300^{\circ}$ gave to $n$ the value two thirds for air and hydrogen. Different values were found by others for other gases and Wiedeman ${ }^{1}$ found that $n$ became smaller with the increase of temperature, a fact also found by Holman. ${ }^{2}$ Schuman ${ }^{3}$ however chose to represent the change by a formula consisting of two factors $\left(\mathrm{I}+\gamma^{\vartheta}\right)^{2} \sqrt{\mathrm{I}+a \vartheta}$ from the consideration that the viscosity is dependent upon two things, the molecular free path and the molecular speed; and while this satisfied his own observations founded upon Maxwell's method, it did not agree with those of Barus. Sutherland ${ }^{4}$ taking into consideration the apparent sphere of action of the molecules as distinguished from the real sphere of action, changed the first factor and represented the change by the equation,

$$
\eta=\eta_{0} \frac{(\mathrm{I}+a c)}{\left(\mathrm{I}+\frac{c}{\theta}\right)} \cdot \sqrt{\mathrm{I}+a \vartheta},
$$

$\theta$ being the absolute temperature, $a$ the coefficient of expansion and $c$ a constant depending on the attractive forces exerted between the molecules when near together. With this he found results agreeing well with Barus and Holman.

Vapors as distinguished from gases proper have also been the subject of observations to determine if they follow the laws of gases as to viscosity. In these researches L. Meyer ${ }^{5}$ and $\mathrm{Koch}^{6}$ have followed the transpiration method while Puluj ${ }^{7}$ and Schumann ${ }^{8}$ have used the oscillation method with the result that at ordinary pressures, like true gases the coefficient of viscosity is independent of the pressure. However the formulæ given for true gases do not here represent exactly the change with the temperature and it seems that

1 Arch. d. Sc. Phys. et Nat., 1876, LVI., p. 273.

2 Proc. Amer. Acad., Boston, I877, XII., p. I ; Phil. Mag. (5), III., p. 8 I ; XXI., p. 199.

3 Wied. Ann., 1884, XXIII., p. 353.

${ }^{4}$ Phil. Mag., I893, (5), 202, p. 507.

5 Wied. Ann., r879, VII., p. 497 ; 1881 , XIII., p. I ; 1882 , XVI., pp. 369, 394.

6 Wied. Ann., I883, XIX., p. 857.

7 Wien. Ber., 1878, LXXVIII., (2), p. 279; Carl's Report, 1878, XIV., p. 573.

8 Wied. Ann., 1884, XXIII., p. 353. 
the viscosity changes in a much larger ratio. Attempts to justify this disagreement have been made wherein the causes which make the laws of a perfect gas differ from the laws of vapors are used for a basis of argument. Of these perhaps the principal one which might be mentioned is the phenomenon of dissociation.

The question of the effect of electric and magnetic fields on the viscosity of a gas has not as yet been very satisfactorily determined, but that these cause no effect would appear from the results of Pagliani ${ }^{1}$ and Noack. ${ }^{2}$ Koenig ${ }^{3}$ oscillated crystal spheres in a magnetic field but the effect on the coefficient of viscosity was not apparently considered. Quincke ${ }^{4}$ also investigated the viscosity of fluids in the electric field, showing an increase without any apparent change in the period of swing of the spheres. To these results however objection was made by Boltzman. ${ }^{5}$ The results of the efforts of investigators to determine the Coefficient of Viscosity of the Air, with the methods used by them may be seen by the table on p. 427 .

As a consequence of the corrections in theory and through the refinements of process the results of the different methods while they varied widely at the start, have been brought into closer harmony. Since no new method differing in principle from these has been given, the only available way of testing the correctness of the results is in a variation of the methods at hand. The method of torsional vibrations seem to permit of a wider range of variation and therefore to be best suited to such a purpose. The objections to the use of discs however has been mentioned as lying in the allowance to be made for the action at the edge of the disc; but the improvement of method in substituting several in place of the one partly obviated this. This objection would not of course hold if a spherical surface were substituted and for this reason as well as that symmetry renders possible a rigorous theoretical development, the sphere or spherical shell seems best suited to answer the requirements.

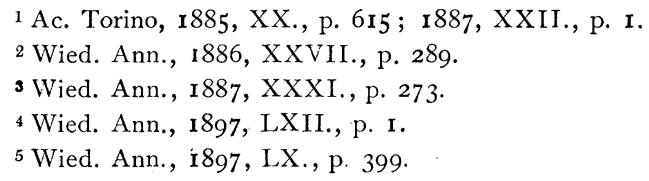


Previous Determinations of the Coefficient of Viscosity of Air.

\begin{tabular}{|c|c|c|c|c|}
\hline Investigator. & Method. & $\begin{array}{l}\text { Coef. } \\
\text { c. G. S. }\end{array}$ & Temp. & Reference. \\
\hline Stokes & Baily's Pendulum & .000104 & & \\
\hline Meyer & Oscillation & .000353 & 0 & Crelle's Jour., 59, p. 229. \\
\hline “6 & Bessel's Exper. & .000273 & & \\
\hline “، & Girault's ، & .000384 & & \\
\hline ، & 66 & .000360 & 18 & \\
\hline “ & Oscillation $\left(2^{\circ}\right)$ & .000333 & 8.3 & Pogg. Ann., r87 ז, CXLIII., p. 14. \\
\hline “ & ، & .000323 & 21.5 & \\
\hline$\because$ & ، & .000366 & 34.4 & \\
\hline “ & Transpiration & .000168 & 0 & Pogg. Ann., 1873, CXLVIII., pp. 37, 203. \\
\hline “ & “ & .000174 & 0 & \\
\hline Maxwell & Oscillation & .000200 & 18 & Phil. Trans., I 866, I 56, p. 249. \\
\hline Puluj & Transpiration & .000179 & 0 & $\begin{array}{l}\text { Wien. Sitz., Abth. 2, I } 874, \text { LXIX., p. } 287 . \\
\text { Wien. Sitz., Abth. 2, I } 874 \text {, LXX., p. } 243 .\end{array}$ \\
\hline Von Obermayer & “ & .000171 & 0 & Carl's Rep., I876, XII., p. I3. \\
\hline ، & ، & .000168 & 0 & $\begin{array}{l}\text { Wien. Sitz., 1875, LXXI., p. } 281 \text {; } 1876 \text {, } \\
\text { LXXIII., p. } 433 .\end{array}$ \\
\hline Schumann & Oscillation & .000168 & 0 & Wied. Ann., I884, XXIII., p. 353. \\
\hline Schneebeli & Transpiration & .000171 & 0 & $\begin{array}{l}\text { Arch. des. Sci. Phys. et Nat. Geneve, r885 } \\
\text { (3), XIV., p. I97. }\end{array}$ \\
\hline Tomlinson & Oscillation (Cylinder) & .000179 & 12.02 & Phil. Trans. (2), 1886, CLXXVII., p. 768. \\
\hline ، & “ & .000176 & 10.64 & \\
\hline ، & 66 & .000177 & 14.63 & \\
\hline “، & “6 & .000178 & 11.69 & \\
\hline “ & (Spheres) & .000176 & 9.97 & \\
\hline
\end{tabular}

BIBLIOGRAPHY

Baily.

Barus.

Phil. Trans., 1832 .

Amer. Jour. Sci., 1888 (3), XXXV., p. 407.

Bull. of the U. S. Geol. Survey, No. 54, Washington, 1889 .

Wied. Ann., I889, XXXVI., p. $35^{8}$.

Bessel.

Phil. Mag., 189o, No. 195, p. 337.

Berl. Akad., I826, Math. Class., p. I.

Boltzman.

Wien. Ber., I872 (2), LXVI., p. 324 ; 1880 (2), LXXXI., p. 117; I88I (2),

LXXXIV., pp. 40, I230; 1887 (2), XCV., p. I53; I887 (2), XCVI., p. 891.

Wied. Ann., r897, LX., p. 399.

Braun and Kurz.

Carls. Rep., I882, XVIII., p. 569; I883, XIX., p. 34.3 .

Breitenbach.

Wied. Ann., I899, LXVII., p. 803.

Annal. d. Phys, I9or, 310, p. r66. 
Brodman.

Clausius.

Wied. Ann., r892, XLV., p. 159.

Couette.

Pogg. Ann., 1858, CV., p. 239.

Compt. Rend., I888, I07, p. 388.

Journ. de Phys., I89o, S. II., T. IX., p. 4I4.

Ann. de Chem. et. Phys., S. VI., T. 21, p. 433

Coulomb.

Mem. de l'Institut, III., pp. 26r, 287.

Crooks.

D'Arcy.

Phil. Trans., I88I, CLXXII., p. 387.

De Heen.

Du Buat.

Mém. des divers savans, I867, XV., p. I4I.

Girault.

Principes d'Hydraulique, $\mathbf{7} 786$.

Graham.

Mem. de l'Acad. de Caen., I860.

Grossman.

Phil. Trans., I846, CXXXVI., pp. 573, 622; 1849, CXXXIX., p. 349.

Pogg. Ann., i 866, CXXVII., pp. 279, 365 .

Inaug. Dis. Breslau, 1880.

Grotrian.

Wied. Ann., I882, p. 619.

Pogg. Ann., i 876, CLVII., pp. I30, 237.

Wied. Ann., I879, VIII., p. 529.

Guthrie.

Hagen.

Phil. Mag., 1878 (5), p. 433

Pogg. Ann., 1839, XLVI., p. 423.

Abth. d. Berl. Akad., I854, p. 17 .

Hagenbach.

Pogg. Ann., 186o, CIX., pp. 385, 40r.

Helmholtz (with Pietrowski).

Wien. Ber., 1860, XL., p. 607.

Heydweiller.

Sitz. d. Phys. Gesell. zu Berlin, I895 (5), p. 33.

Hoffman.

Holman.

Wied. Ann., 1884, XXI., p. 470.

Proc. Amer. Acad. Boston, 1877, XII., p. 4I ; 1886, XXI., p. 1.

Houdaille.

Phil. Mag., I877 (5), III., p. 8I ; I886, XXI., p. 199.

Fortschr. der Phys., 1896, 52, Jahr. I., p. 442.

Klemencice.

Carls. Rep., I88I, XVII., p. I44.

Wien. Ber. $1882(2), 84$, p. 146.

Beibläertt, I882, 6, p. 66 . 
Kirchoff.

Mechanik, 1877 , 2. Aufl. 26, Vor., p. 38 r.

Koch.

Koenig.

Wied. Ann., I883, XIX., p. 857 .

Wied. Ann., 1885, XIV., p. 6r8; 1887, XXXI., p. 273; r887, XXXII., p. 193.

Sitz. d. München. Ak., I 887 , XVII., p. 343 .

Kundt and Warburg.

Monatsber. d. Berl. Akad., 1875, p. 160.

Pogg. Ann., 1875, CLV., pp. 337, 525.

Lampe.

Lampel.

Programm des Städt Gym. zu Danzig, I866.

Wien. Ber., I886, XCIII. (2), p. 29 r.

Lang.

Wien. Ber., I87 I, LXIV. (2), p. 485.

Pogg. Ann. I87I, CXLV., p. 290.

Margules.

Wien. Ber., 1881, LXXXIII., p. 588.

Maxwell.

Phil. Mag., I860 (4), XIX., p. 31 ; I868 (4), XXV., p. 209.

Phil. Trans., I866, CLVI., p. 249.

Collected Papers, vol. II.

Proc. Royal Soc., I866, XV., p. 14.

Meyer, Lothar.

Wied. Ann., 1882, XVI., p. 394 ; r885, XXV., p. 340.

Meyer, L., and Schumann.

Wied. Ann., I881, XIII., p. I.

Meyer, 0 .

Crelle's Journal, I861, LIX., p. 237.

Pogg. Ann., 1861, CXIII., p. 85 ; 1865, CXXV., p. 177; 1866, CXXIII., pp. 253, 353, 367; 1871, CXLII., p. 513; 1871, CXLIII., p. 14; 1873, CXLVIII., p. 203.

Wied. Ann., I879, VII., p. 497; I88I, XIII., p. I ; I882, XVI., p. 394

I887, XXXII., p. 642 ; I891, XLIII., p. I.

Phil. Mag. I886 (2I), p. 220

Sitz. d. München Ak., 1887, XVII., p. 343.

Meyer, 0., and Springmühl.

Mützel.

Pogg. Ann., I873, CXLVIII., pp. 1, 503, 526.

Wied. Ann., I89I, XLIII., p. I5.

Navier.

Mem. de l'Acad. des Sciences, 1823 , Tom. VI., p. 389 ; I830, IX., p. 336.

Neuman.

Newton.

Einl. in d. theor. Physik., p. 246.

Noack.

Phil. nat. princ. math., I687, Lib. II., Sect. 9.

Wied. Ann, r886, XXVII., 289. 
Obermayer.

Wien. Ber., I 875 (2), LXXI., p. 28I ; I875 (2), LXXIII., p. 433

Carls. Rep., I876 (2), XII., pp. I3, 456; 1877 , XIII., p. I3o.

Pachu and Finazzi.

Nuovo Cimenti, April, r9oo, XI., pp. 290, 294.

Atti del R. Instituto Veneto di Scienzi, I900, LIX., pp. 389-403. Pagliani.

Ac. Torino, 1885, XX., p. 61 5 ; 1887, XXII., p. х.

Poiseuille.

Soc. Philomath, 1838, p. 77 ; Comptes rendus, I840, XI., pp. 96I, 104I ;

I841, XII., p. II2; I842, XV., p. 1167.

Ann. Chem., 1843 (3), VII., p. 50.

Mém. de savans étrangers, I846, IX., p. 433 .

Poisson.

Puluj.

Journal de l'école Polytech., 183\%, XIII., p. I39.

Wien. Ber., I874, LXIX. (2), p. 287 ; LXX. (2), p. 243 ; 1876, LXXIII. (2), p. 589 ; 1878 , LXVIII. (2), p. 279.

Carl's Rep., I878, XIV., p. 573.

Phil. Mag., 1878 (5), VI., p. 157.

Quincke.

Wied. Ann., I880, X., pp. I6I, 394, 513; I883, XIX., pp. 545, 750; I885, XXIV., pp. 347,606 ; I886, XXVIII., p. 529 ; 1888, XXXIV., p. 401 ; 1896, LIX., p. 417 ; 1897 , LXII., p. I.

Rells'ab.

Inaug. diss. Bonn., 1868 .

Reynolds.

Royal Inst. of Gt. Brit., r884, p. r.

Beiblätter, I886, X., p. 217.

Rutherford.

Schmidt.

Phil. Mag., I 897, 209, p. 240.

Schultze.

Wied. Ann., I877, II., pp. 48, 24I ; 1882, XVI., p. 633.

Stefan.

Wied. Ann., I884, XXIII., p. 353.

Steudel.

Wien. Ber., I862 (2), XLVI., p. 495 ; 1872 (2), LXV., p. 360.

Stokes.

Wied. Ann., r882, XVI., p. 369.

Camb. Phil. Trans., I849, VIII., p. 287 ; I850 (2), IX., p. 8 ; 1881, CLXXII., p. 435 .

Sprung.

Phil. Mag., I85I (4), I., p. 337.

Pogg. Ann., r876, CLIX., p. r.

Sutherland.

Proc. Amer. Acad., I885, pp. I3, I6.

Phil. Mag., I 893 (5), 202, p. 507. 
Thomson and Rutherford.

Phil. Mag., 1896. 208, p. 392; I893, 202, p. 313.

Tomlinson.

Phil. Trans., I886 (2), I77, p. 767.

Warburg.

Pogg. Ann., r876, CLIX., p. 403.

Warburg and Babo.

Wied. Ann., I882, XVII., p. 390.

Sitz. d. Berl. Akad., I882, p. 509.

Wiedemann.

Pogg. Ann., I856, XCIX., p. 177.

Arch. d. Sc. Phys. et Nat., 1876, LVI., p. 273.

Fortschr. d. Phys., I876, XXXII., p. 266.

Wilberforce.

Phil. Mag., I89I (5), XXXI., p. 407.

(To be continued.) 